\title{
NUP98/11p15 translocations affect CD34+ cells in myeloid and T lymphoid leukemias
}

\author{
Barbara Crescenzi ${ }^{a}$, Valeria Nofrini ${ }^{a}$, Gianluca Barba ${ }^{a}$, Caterina Matteucci ${ }^{a}$, \\ Danika Di Giacomo ${ }^{\mathrm{a}}$, Paolo Gorello ${ }^{\mathrm{a}}$, Berna Beverloo ${ }^{\mathrm{b}}$, Antonella Vitale ${ }^{\mathrm{c}}$, \\ Iwona Wlodarska ${ }^{\mathrm{d}}$, Peter Vandenberghe ${ }^{\mathrm{d}}$, Roberta La Starza ${ }^{\mathrm{a}}$, Cristina Mecucci ${ }^{\mathrm{a}, *}$ \\ a Laboratory of Molecular Medicine, CREO, University of Perugia and A.O. Perugia, 06132 Perugia, Italy \\ ${ }^{b}$ Department of Clinical Genetics, Erasmus MC, 3000 CB Rotterdam, The Netherlands \\ ${ }^{\mathrm{c}}$ Hematology, Department of Cellular Biotechnologies and Hematology, La Sapienza University, Via Benevento 6, 06161 Rome, Italy \\ d Center for Human Genetics, K.U. Leuven, Gasthuisberg, Herestraat 49, Box 602, B-3000 Leuven, Belgium
}

\section{A R T I C L E I N F O}

\section{Article history:}

Received 17 November 2014

Received in revised form 5 March 2015

Accepted 22 April 2015

Available online xxx

\section{Keywords:}

NUP98 translocations

Leukaemia

Lineage affiliation

Single cell analysis

\begin{abstract}
A B S T R A C T
We assessed lineage involvement by NUP98 translocations in myelodysplastic syndromes (MDS), acute myeloid leukaemia (AML), and T-cell acute lymphoblastic leukaemia (T-ALL). Single cell analysis by FICTION (Fluorescence Immunophenotype and Interphase Cytogenetics as a Tool for Investigation of Neoplasms) showed that, despite diverse partners, i.e. NSD1, DDX10, RAP1GDS1, and LNP1, NUP98 translocations always affected a CD34+/CD133+ hematopoietic precursor. Interestingly the abnormal clone included myelomonocytes, erythroid cells, B- and T- lymphocytes in MDS/AML and only CD7+/CD3+ cells in T-ALL. The NUP98-RAP1GDS1 affected different hematopoietic lineages in AML and T-ALL. Additional specific genomic events, were identified, namely FLT3 and CEBPA mutations in MDS/AML, and NOTCH1 mutations and MYB duplication in T-ALL.
\end{abstract}

(c) 2015 Elsevier Ltd. All rights reserved.

\section{Introduction}

NUP98 is a member of the nucleoporin protein family which constitutes the nuclear pore complex, the large channel spanning the nuclear envelope to mediate nucleocytoplasmic transport [1]. Since the NUP98-HOXA9 fusion deriving from recurrent $\mathrm{t}(7 ; 11)(\mathrm{p} 15 ; \mathrm{p} 15)$ was first identified in acute myeloid leukaemia (AML) [2,3], more than 30 NUP98 partners have been identified in the myelodysplastic syndrome (MDS), acute myeloid leukaemia (AML), chronic myeloid leukaemia in blastic phase (BP-CML), and T-cell acute lymphoblastic leukaemia (T-ALL) [4]. No NUP98 fusions have been detected in B cell lymphoid malignancies, sofar. The NUP98 amino-terminal portion containing FG repeats always participates in fusion proteins while the partner gene provides the C-terminal portion. Despite the heterogeneity, NUP98 partners fall into the two main categories of homeodomain genes (HD) and non-HD genes. Notably, in mouse models HD partners confer oncogenetic properties to a significantly greater extent than non-HD partners [5].

\footnotetext{
* Corresponding author at: Laboratory of Molecular Medicine, CREO, University of Perugia and A.O.Perugia, Piazza Menghini 9, 06132 Perugia, Italy. Tel.: +39075 5783808; fax: +39075 5783691

E-mail address: cristina.mecucci@unipg.it (C. Mecucci).
}

In T-ALL only 3 partners (SETBP1, CCDC28A, RAP1GDS1) have been described to date while 2 others ( $A D D 3$ and $I Q C G)$ were reported to be involved in biphenotypic myeloid/T leukaemia. A specific fusion such as NUP98/NSD1 is only found in MDS and AML [4]. Despite these results the role of fusion partners in determing disease phenotype is not fully clarified.

To explore this issue we used FICTION (Fluorescent Immunophenotype and Interphase Cytogenetic as a Tool for Investigation of Neoplasms) as a single cell analysis to investigate expression of myeloid and lymphoid lineage specification antigens in leukemic cells bearing NUP98 translocations.

\section{Materials and methods}

\subsection{Patients}

9 patients ( 5 males, 4 females; age range: $16-65$ ) with $11 \mathrm{p} 15 /$ NUP98 positive haematological malignancies (2 MDS-RAEB, 5 AML, and 2 T-ALL) were recruited at the Haematology Departments, Universities of Perugia and Rome (Italy), Centre for Human Genetics, University of Leuven (Belgium), and the Department of Clinical Genetics, Erasmus University of Rotterdam (The Netherlands)(Table 1). The identity of several fusion partners has already been reported elsewhere [6-11]. All patients gave their informed consent to sample collection and biological analyses in accordance with the Declaration of Helsinki. The study was approved by the Bioethics Committee, University of Perugia (Prot.1.X.2011). 
Table 1

Clinical, haematological, cytogenetic and molecolar features of patients with NUP98 translocations.

\begin{tabular}{|c|c|c|c|c|c|c|c|}
\hline Cases & $\mathrm{S} / \mathrm{A}$ & Diagnosis & $\begin{array}{l}\text { CD34+ cells } \\
(\%)\end{array}$ & Karyotype & NUP98 partner & SNPa & Mutations \\
\hline 1 & $\mathrm{M} / 36$ & RAEB2 & 51 & $46, \mathrm{XY}[20]$ & NSD1 & normal & $\begin{array}{l}\text { FLT3-ITD; CEBPA } \\
\text { (c.1004 T>C p.L335P) }\end{array}$ \\
\hline 2 & $\mathrm{M} / 65$ & RAEB & n.a. & 46,XY,add(11)(p15)[17]/46,XY[3] & NSD1 & $\begin{array}{l}\text { LOSS: } 15 q 26.1 \text { LOH: } \\
\text { 6q24.2-q25.2, } \\
\text { 13q12.3-q14.1, } \\
\text { 16q11.2-q21, } \\
\text { 19p13.1-p13.3 }\end{array}$ & - \\
\hline 3 & $\mathrm{~F} / 31$ & AML & 86 & $46, \mathrm{XX}[20]$ & NSD1 & LOSS: 9p21.2-p21.3 & FLT3-ITD \\
\hline 4 & $\mathrm{M} / 39$ & AML-M4 & 1 & $\begin{array}{l}\text { 30-45,XY,-1[3],-9[4],- } \\
\text { 10[4],inv(11)(p15q22)[10],-15[3],- } \\
\text { 17[4],-18[4],-19[4],-20[4],-- } \\
21[4][\text { cp10] }\end{array}$ & DDX10 & n.a. & - \\
\hline 5 & $\mathrm{M} / 28$ & AML-M2 & 73 & 46,XY,t(3;11)(q12;p15)[15] & LNP1 & n.a. & FLT3-ITD \\
\hline 6 & $\mathrm{~F} / 36$ & AML-M2 & 1 & $46, X X, \mathbf{t}(\mathbf{1 1} ; \mathbf{1 2})(\mathbf{p} 15 ; \mathbf{q 1 3})[15]$ & unknown & n.a. & - \\
\hline 7 & $\mathrm{~F} / 60$ & AML-M0 & 90 & $\begin{array}{l}\text { 46-47,XX,t(1;17)(q22;q11),t(4;11) } \\
\text { (q1?3;p15),?der(8)(p?)[7], } \\
\operatorname{del}(11)(\mathrm{p} 12 \mathrm{p} 1 ? 3)[6], \operatorname{del}(12) \\
\text { (p11p13),add(14)(q3?2)[7],p15[3], } \\
\operatorname{del}(15)(\mathrm{q} 1 ? 3 \mathrm{q} 2 ? 2)[\mathrm{cp} 22] / 46, \mathrm{XX}[4]\end{array}$ & RAP1GDS1 & $\begin{array}{l}\text { LOSS: } 2 \mathrm{p} 25.2,3 \mathrm{q} 23, \\
5 \mathrm{q} 13.3-\mathrm{q} 14.1,5 \mathrm{q} 22.1, \\
\text { 11p13, 12p11.2-p13.3, } \\
\text { 15q11.2-q21.1, } \\
\text { 16q12.1, 17q11.2-q12, } \\
19 \mathrm{q} 13.1,21 \mathrm{q} 21.1\end{array}$ & - \\
\hline 8 & $\mathrm{~F} / 16$ & T-ALL & 0 & $47, X X, \mathbf{t}(\mathbf{4} ; 11)(\mathbf{q} 21 ; \mathbf{p} 15),+8[20]$ & RAP1GDS1 & $\begin{array}{l}\text { GAIN: 6q23.3, } \\
\text { chromosome } 8\end{array}$ & $\begin{array}{l}\text { NOTCH1 } \\
\text { (c.7200_7201ins(GGGAA); } \\
\text { p.N2401Gfs*23 } \\
\text { c.7318C }>\text { T p.Q2440* }\end{array}$ \\
\hline 9 & $\mathrm{M} / 25$ & T-ALL & 20 & $\begin{array}{l}\text { 46,XY,t(4;11)(q21;p15),del(5) } \\
(\mathrm{q} 31 \mathrm{q} 35), \operatorname{der}(16) \mathrm{t}(\mathrm{X} ; 16) \\
(\mathrm{p} 11 ; \mathrm{p} 13)[12]\end{array}$ & RAP1GDS1 & $\begin{array}{l}\text { LOSS: 5q23.2-q35.3, } \\
\text { 16p13.1-p13.3 GAIN: } \\
\text { 5p13.3-p15.33, 6q23.3, } \\
\text { Xp21.1-q22.3 }\end{array}$ & $\begin{array}{l}\text { NOTCH1 } \\
\text { (c.4672G>A,p.G1558R; } \\
\text { c.7403_7408 } \\
\text { delinsCCCGCGCAAGGGGC, } \\
\text { p.L2468Pfs*11) }\end{array}$ \\
\hline
\end{tabular}

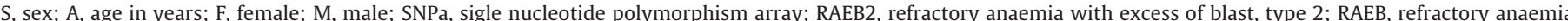

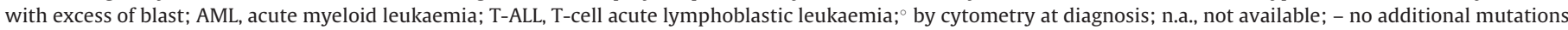
identified.

\subsection{Fiction}

FICTION was performed as already described [12], using the following mouse monoclonal antibodies: anti-CD33, CD3, CD7, CD19, CD20, Glycophorin A (Dako, Milan, Italy), anti-CD34, CD13, CD14 (Becton-Dickinson, Milan, Italy), and antiCD133 (Miltenyi Biotec S.r.l., Bologna, Italy) antigens and a three-step staining technique with Cy3-conjugated polyclonal antibodies. NUP98 gene was investigated with two genomic clones (RP11-348A20 and CTD-3234FF16F, both labelled with Spectrum green) encompassing the full gene. Immunophenotype and hybridization signals were simultaneously identified and counted on 10-100 cells for each antibody, using an Olympus fluorescence microscope equipped with a double band filter, a CCD camera (Sensys-Photometrics, Tucson AZ, USA) and image analysis software (Vysis, SmartCapture, Olympus, Milan, Italy). Two healthy donors were used as normal controls. The cut-off for NUP98 translocation ( 3 signals) was established at the upper limit of normal controls. All slides were evaluated by two independent observers. Data are reported as the means of results.

\subsection{SNP array and Interphase FISH}

Single Nucleotide Polymorphism-Array (SNPa) was performed with CytoScan HD Affymetrix platform, following the manufacturer's instructions. $250 \mathrm{ng}$ of high quality genomic DNA obtained from unsorted bone marrow cells of patients nos 1-3 and 7-9 (Table 1) was used to study Copy Number Alterations (CNAs) and copy neutral loss of heterozygosity ( $\mathrm{cnLOH}$ ). Protocol was supported by Affymetrix GeneChip Command Console (AGCC) software. Analysis was performed with Affymetrix Chromosome Analysis Suite 2.0 (ChAS) software. For accurate state detection, filters were set at $100 \mathrm{~kb}$ dimension for CNAs and $10 \mathrm{Mb}$ dimension for $\mathrm{cnLOH}$. Our data refer to NetAffx Build 32.3 (hg19) database. Polymorphic copy-number variations were excluded from analysis (Database of Genomic variants: http:// projects.tcag.ca/variation/). Interphase FISH (I-FISH) with fosmids G248P89100B2, encompassing $M Y B$, and G248P89828A1, flanking the $3^{\prime} M Y B$, was done in case no. 9 .

\subsection{Mutational analysis}

Mutational analysis was performed on DNA obtained from patients' unsorted bone marrow cells. The CEBPA, TP53, and TET2 whole coding sequences were analyzed by DHPLC. NOTCH1 (exons 26,27,34), FLT3 (ITD and D835Y), PU.1 (exon 3), SETBP1 (exon 4), GATA1 (exon 2), GATA2 (exons 3,4,5,6,7), GATA3 (exons 4,5,6), and DNMT3A (exons $15,19,20,21,22,23$ ) were investigated by Sanger sequencing.

\section{Results}

\subsection{Fiction}

FICTION results are summarized in Table 2. Representative images of FICTION experiments in patient no. 1 are showed in Fig. 1. In MDS and AML (patients nos. 1-7), NUP98+ cells were expressed in the myelomonocytes (range: $60-94 \%$ for CD33+; $31-100 \%$ for CD13+, 60-90\% for CD14+), the erythroid lineage (33-100\% for Glyc A+), B- cells (39-69\% for CD20+; 35-74\% for CD19+) and T cells (13-76\% for CD7+; $42-70 \%$ for CD3+).

In T-ALL (patients nos. 8 and 9) only $\mathrm{T}$ cells were involved (83-90\% CD7+ and 100\% CD3+) downstream to CD34+/CD133+ hematopoietic precursors.

\subsection{SNP array and I-FISH}

A total of 24 events were detected in 6/9 patients, $20 \mathrm{CNVs}$ (5 gains; 15 losses) and 4 cnLOHs. Both patients with NUP98+ T-ALL (cases nos. 8 and 9, Table 1) presented a small gain at chromosome $6 \mathrm{q} 23.3$, corresponding to MYB gene duplication. In case no. 9, I-FISH detected MYB tandem duplication in about $50 \%$ of nuclei.

\subsection{Mutational analysis}

NOTCH1 mutations were found only in T-ALL cases (cases nos. 8 and 9). In patient no. 8 we observed c.7200_7201ins(GGGAA) p.N2401Gfs*23 and the recurrent c.7318C $>$ T p.Q2440*, both in the PEST domain. In patient no. 9 we detected c.4672G $>A$, p.G1558R (HD domain) and c.7403_7408delinsCCCGCGCAAGGGGC, p.L2468Pfs*11 (PEST domain) (Table 1). CEBPA analysis showed patient no. 1 (RAEB2) carried a novel heterozygous missense $C$ terminal mutation c.1004T >C p.L335P(Table 1). FLT3-ITD was found 
Table 2

FICTION results.

\begin{tabular}{|c|c|c|c|c|c|c|c|c|c|c|c|}
\hline & case 1 & case 2 & case 3 & case 4 & case 5 & case 6 & case 7 & case 8 & case 9 & control 1 & control 2 \\
\hline CD34 & 92/99 (93) & $13 / 36(36)$ & $86 / 100(86)$ & $34 / 47$ (72) & $57 / 92(62)$ & $9 / 13$ (69) & $32 / 40(80)$ & $14 / 15(93)$ & $50 / 53(94)$ & $2 / 50(4)$ & $0 / 50(0)$ \\
\hline CD133 & 40/51 (78) & $18 / 31(58)$ & - & $20 / 30(67)$ & $40 / 53(75)$ & - & $22 / 26(85)$ & $20 / 30(67)$ & - & $0 / 54(0)$ & $1 / 42(2)$ \\
\hline CD33 & $94 / 100(94)$ & $50 / 83(60)$ & $50 / 53(94)$ & $55 / 72(76)$ & $28 / 30(93)$ & - & $60 / 100(60)$ & $1 / 25(4)$ & - & $2 / 60(3)$ & $2 / 56(4)$ \\
\hline CD13 & $90 / 100(90)$ & $70 / 100(70)$ & $85 / 110(77)$ & $50 / 83(60)$ & $41 / 62(66)$ & - & $24 / 78(31)$ & $2 / 52(4)$ & $0 / 20(0)$ & $0 / 40(0)$ & $2 / 52(4)$ \\
\hline CD14 & $36 / 49(74)$ & $60 / 100(60)$ & - & $70 / 78(90)$ & $60 / 90(67)$ & - & $20 / 30(67)$ & $0 / 31(0)$ & - & $0 / 52(0)$ & $0 / 50(0)$ \\
\hline Glycophorin A & $90 / 106(85)$ & $70 / 93(75)$ & $0 / 40(0)$ & $31 / 40(78)$ & $10 / 10(100)$ & - & $23 / 70(33)$ & $2 / 39(5)$ & $0 / 16(0)$ & $0 / 55(0)$ & $4 / 85(5)$ \\
\hline CD3 & $0 / 100(0)$ & $70 / 100(70)$ & $0 / 34(0)$ & $22 / 53(41)$ & $0 / 22(0)$ & $0 / 50(0)$ & $13 / 29(45)$ & $38 / 38(100)$ & $100 / 100(100)$ & $0 / 60(0)$ & $0 / 63(0)$ \\
\hline CD7 & $15 / 110(13)$ & $60 / 100(60)$ & $0 / 80(0)$ & $23 / 30(76)$ & $1 / 45(2)$ & $0 / 52(0)$ & $40 / 80(50)$ & $50 / 60(83)$ & $100 / 110(90)$ & $1 / 52(2)$ & $0 / 70(0)$ \\
\hline CD20 & $0 / 100(0)$ & $50 / 100(50)$ & - & $34 / 49$ (69) & $1 / 25(4)$ & - & $22 / 36(39)$ & $1 / 30(3)$ & $0 / 30(0)$ & $0 / 35(0)$ & $2 / 50(4)$ \\
\hline CD19 & $0 / 100(0)$ & $40 / 100(40)$ & - & $57 / 77(74)$ & $0 / 46(0)$ & - & $8 / 23(35)$ & $1 / 24(4)$ & - & $2 / 44(5)$ & $0 / 36(0)$ \\
\hline
\end{tabular}

Case number refers to Table 1 . Number of positive/total cells (percentage); -, not done.
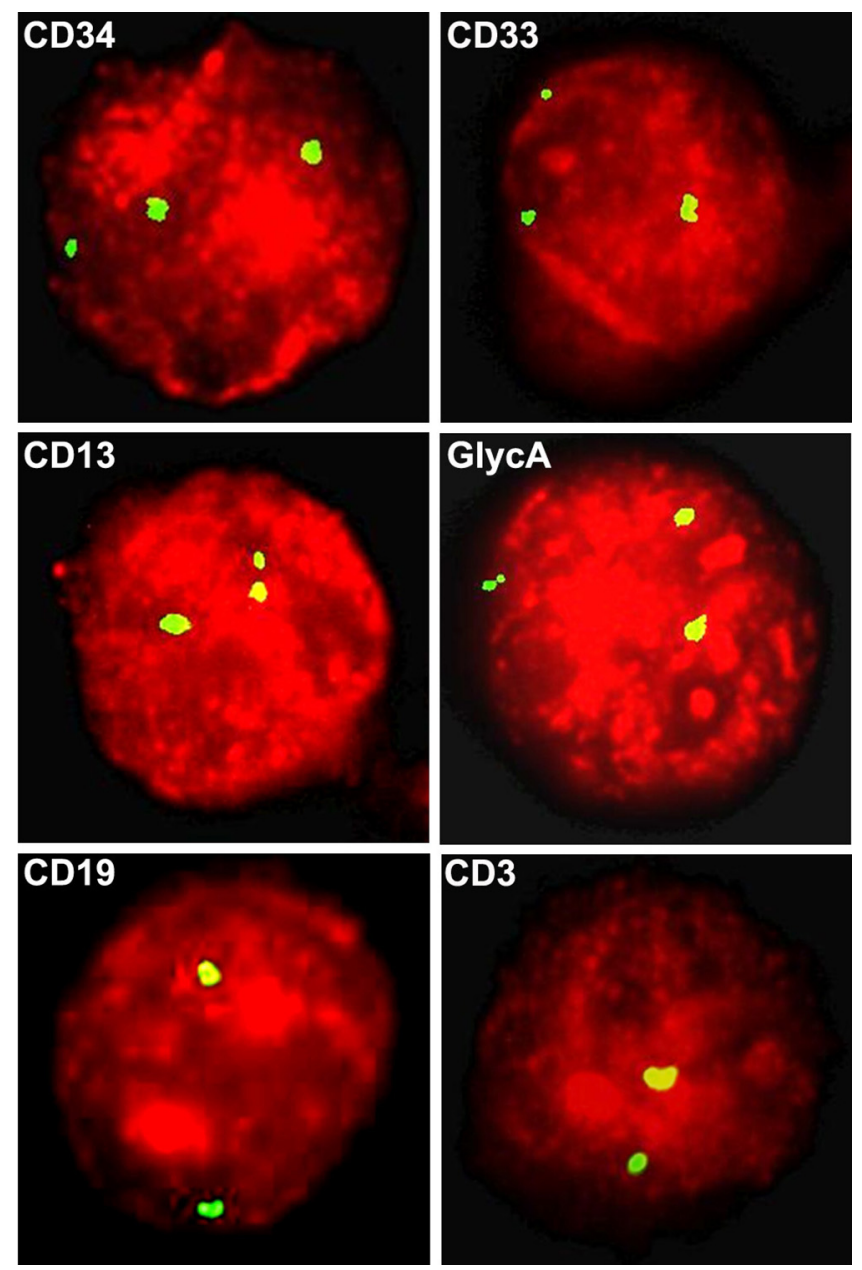

Fig. 1. FICTION (Fluorescence Immunophenotype and Interphase Cytogenetics as a Tool for Investigation of Neoplasms) on intact cells in MDS with NUP98 translocation (patient no. 1). FICTION with monoclonal antibodies against CD34, CD33, CD13, Glycophorin A, CD19, CD3 (red). Red staining detects positive intact cells expressing the specific antigen. Green spots indicate FISH signals in the nuclei using a FITC labelled genomic probe for NUP98. Two green signals indicate normal disomic cells; three show NUP98 split because of translocation (magnification $1.000 \times$ ). (For interpretation of the references to color in this figure legend, the reader is referred to the web version of this article.)

in three cases, two with NUP98-NSD1 and one with NUP98-LNP1 (Table 1). No mutations were detected in the TP53, TET2, PU.1, SETBP1, GATA1, GATA2, GATA3, and DNMT3A genes (data not shown).

\section{Discussion}

The present study was designed to gain insights into clonal cells that are affected by NUP98 leukemic translocations and to investigate whether NUP98 partners play a role in the leukemic phenotype. FICTION, the technique we used, was previously validated as a reliable qualitative single cell analysis for characterizing the leukemic bulk in genetic entities [12-15]. It combined immunostaining with monoclonal antibodies against lineage specification antigens with in situ hybridization of DNA probes to detect genomic lesions in our 9 representative cases (7 MDS/AML and 2 T-ALL) of NUP98 positive malignancies affecting myeloid and T-cell leukemias.

Studying four NUP98 translocations with partners NSD1, DDX10, LNP1, and RAP1GDS1 we showed that all NUP98 translocations were present in CD34+/CD133+ hematopoietic precursors in both MDS/AML and T-ALL, even when cases displayed no evidence of CD34 expression at diagnostic cytometry (Table 1 , cases nos. 4, 6,8). Interestingly, a CD34+ multi-potent progenitor was reported to be involved in well established cytogenetic-molecular MDS/AML subtypes, such as those bearing PML-RARA, RUNX1-ETO, inv(3), 5q-, +8 and monosomy 7 [16-21]. As far as we know present results are the first observation of a specific genetic lesion in the CD34+ cells of T-ALL.

The present investigation found the CD34+/CD133+ precursors that were affected by a NUP98 translocation were restricted to different lineages in MDS/AML and in T-ALL. In fact, only CD3+ CD7+ cells were involved in T-ALL while, despite inter-individual variations, myelomonocytic, erythroid, $B$ and $T$ lineages were involved in MDS/AML (Table 2 and Fig. 1). Interestingly one case of AML (no. 7) and one case of T-ALL (no. 8), showed the RAP1GDS1 NUP98 partner with the same exon 2 fusion point $[10,11]$, suggesting the leukaemia phenotype could have been addressed by additional (epi)genetic or microenvironmental events.

In the search for additional events we performed SNPa and mutational analysis on 11 candidate genes in our series. We found 6q23.3/MYB tandem duplication and NOTCH1 gain-of-function mutations in T-ALL (Table 1, cases nos. 8 and 9). MYB deregulation is recognized as a leukemogenic event in a T-ALL subgroup with $M Y B / 6 q 23.3$ tandem duplication/gain or translocation with the TCR gene [22]. NOTCH1 activation initiates the T-cell differentiation programme of uncommitted precursors in the thymic stroma [23] and NOTCH1 mutations are an established oncogenic event in T-ALL [24]. As expected, NOTCH1 mutations were not found in our cases of MDS/AML.

In MDS/AML we identified FLT3-ITD (Table 1, cases nos. 1, 3 and 5) and a mono-allelic CEBPA mutation, involving the C-terminal DNA binding domain (Table 1, case no. 1). The myeloid effects of FLT3 and CEBPA mutations were proven in in vivo models. FLT3ITD induced myeloid progenitor expansion in mice [25] and strong synergism between NUP98-NSD1 fusion and FLT3-ITD increased proliferation and promoted self-renewal with short latency to AML development [26]. Moreover Kato et al. [27], using a BMT (Bone Marrow Transplantation) model, provided evidence for the oncogenic properties of a C-terminal CEBPA mutation and for its collaboration with FLT3-ITD in AML induction. 


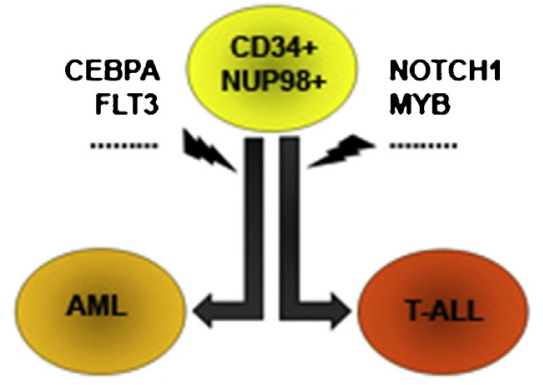

Fig. 2. Proposed schematic representation for T-ALL and AML bearing NUP98 translocations. NUP98 affects CD34 precursors. An additional genetic change like FLT3-ITD or CEBPA mutations pulls leukemogenesis towards MDS/AML while

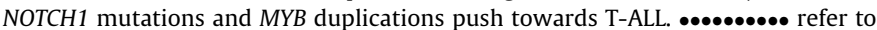
hypothetical additional events that remain to be discovered.

Our results are schematically represented in Fig. 2 suggesting that additional mutations contributed to the phenotypic expression of NUP98 rearranged leukemias.

\section{Conclusions}

This ex vivo study provided evidence that NUP98 translocations are early leukemic lesions which affect a CD34+ precursor. Myeloid or T-lymphoid leukemic immunophenotypes were not addressed by RAP1GDS1 gene as translocation partner. New insights into additional lineage specific genetic events associated with NUP98 translocation in both T-ALL and MDS/AML were provided.

\section{Conflict of interest statement}

The authors reported no potential conflicts of interest.

\section{Acknowledgements}

$\mathrm{CM}$ is supported by Fondo per gli investimenti della Ricerca di Base (FIRB 2011 RBAP11TF7Z-005), Associazione italiana per la Ricerca sul Cancro (AIRC I.C. 11512), Fondazione Cassa di Risparmio, Perugia (2014.0265.021) Programmi di ricerca scientifica di rilevante interesse nazionale (PRIN 08010101).

Contributions: $\mathrm{CM}$ and $\mathrm{BC}$ conceived the study and wrote the paper. VN, GB, CaM, DDG, PG, RLS, CM analyzed and interpretated data. BB, AV, IW, PV provided patients samples. All authors contributed to the final approved version of this report.

\section{References}

[1] Capelson M, Hetzer MW. The role of nuclear pores in gene regulation, development and disease. EMBO 2009;10:697-705.

[2] Borrow J, Shearman AM, Stanton Jr VP, Becher R, Collins T, Williams AM, et al. The $t(7 ; 11)(p 15 ; p 15)$ translocation in acute myeloid leukaemia fuses the genes for nucleoporin NUP98 and class I homeoprotein HOXA9. Nat Genet 1996;12:159-67

[3] Nakamura T, Largaespada DA, Lee MP, Johnson LA, Ohyashiki K, Toyama K, et al. Fusion of the nucleoporin gene NUP98 to HOXA9 by the chromosome translocation $\mathrm{t}(7 ; 11)(\mathrm{p} 15 ; \mathrm{p} 15)$ in human myeloid leukaemia. Nat Genet 1996;12:154-8.

[4] Gough SM, Slape CI, Aplan PD. NUP98 gene fusions and hematopoietic malignancies: common themes and new biologic insights. Blood 2011:118:6247-57.

[5] Saw J, Curtis DJ, Hussey DJ, Dobrivic A, Aplan PD, Slape CI. The fusion partner specifies the oncogenic potential of NUP98 fusion proteins. Leuk Res 2013;37:1668-73.
[6] La Starza R, Gorello P, Rosati R, Riezzo A, Veronese A, Ferrazzi E, et al. Cryptic insertion producing two NUP98/NSD1 chimeric trascripts in adult refractory anemia with excess of blasts. Genes Chromosomes Cancer 2004;41: 395-9.

[7] Gorello P, Nofrini V, Brandimarte L, Pierini V, Crescenzi B, Nozza F, et al. $\operatorname{Inv}(11)(\mathrm{p} 15 \mathrm{q} 22) /$ NUP98-DDX10 fusion and isoforms in a new case of de novo acute myeloid leukemia. Cancer Genet 2013;206:92-6

[8] Gorello P, Brandimarte L, La Starza R, Pierini V, Bury L, Rosati R, et al. Mecucci C. $\mathrm{t}(3 ; 11)(\mathrm{q} 12 ; \mathrm{p} 15) /$ NUP98-LOC348801 fusion transcript in acute myeloid leukemia. Haematologica 2008;93:1398-401

[9] La Starza R, Brandimarte L, Pierini V, Nofrini V, Gorello P, Crescenzi B, et al. NUP98-positive acute myeloid leukemia with a $\mathrm{t}(11 ; 12)(\mathrm{p} 15 ; \mathrm{q} 13)$ without HOXC cluster gene involvement. Cancer Genet Cytogenet 2009;193:109-11.

[10] Van Zutven LJ, Onen E, Velthuizen SC, Van Drunen E, Von Bergh AR, Van Den Heuvel-Eibrink MM, et al. Identification of NUP98 abnormalities in acute leukemia: JARIDIA (12p13) as a new partner gene. Genes Chromosomes Cancer 2006; $45: 437-46$

[11] Mecucci C, La Starza R, Negrini M, Sabbioni S, Crescenzi B, Leoni P, et al. $\mathrm{t}(4 ; 11)(\mathrm{q} 21 ; \mathrm{p} 15)$ traslocation involving NUP98 and RAP1GDS1 genes: characterization of a new subset of $\mathrm{T}$ acute lymphoblastic leukemia. Br J Haematol 2000;109:788-93.

[12] Crescenzi B, Chase A, La Starza R, Beacci D, Rosti V, Gallì A, et al. FIP1L1PDGFRA in CEL and BCR-ABL1 in CML affect different leukemic cells. Leukemia 2007;21:397-402.

[13] Weber-Matthiesen K, Deeberg J, Muller-Hermelink A, Schlegelberger B, Grote W. Rapid immunophenotypic characterization of chromosomally aberrant cells by the new FICTION method. Cytogenet Cell Genet 1993;63 123-5.

[14] Martin Subero JI, Gesk S, Harder L, Grote W, Siebert R. Interphase cytogenetics of haematological neoplasms under the perspective of the novel WHO classification. Anticancer Res 2003;23:1139-48.

[15] Crescenzi B, La Starza R, Nozzoli C, Ciolli S, Matteucci C, Romoli S, et al Molecula cytogenetic findings in a four-way $\mathrm{t}(1 ; 12 ; 5 ; 12)(\mathrm{p} 36 ; \mathrm{p} 13 ; \mathrm{q} 33 ; \mathrm{q} 24)$ underlying the ETV6-PDGFRB fusion gene in chronic myelomonocytic leukemia. Cancer Genet Cytogenet 2007;176:67-71

[16] Chang H, Ying Qi X, Sutherland R. Identification of cell lineages involved by $\mathrm{t}(15 ; 17)$ in acute promyelocytic leukaemia by combined fluorescence activated cell sorting and FISH. Cancer Genet Cytogenet 2005;158:43-8.

[17] Miyamoto T, Weissman IL, Akashi K. AML1/ETO-expressing nonleukemic stem cells in acute myelogenous leukemia stem cells in acute myelogenous leukemia with 8;21 chromosomal traslocations. PNAS 2000;97:7521-6.

[18] Shi G, Weh HJ, Duhrsen U, Zeller W, Hossfeld DK. Chromosomal abnormality inv(3)(q21;q26) associated with multilineage hematopoietic progenitor cells in hematopoietic malignancies. Cancer Genet Cytogenet 1997;96: 58-63.

[19] Nilsson L, Astrand-Grundstrom I, Ardvidsson I, Jacobsson B, Hellström-Lindberg E, Hast R, et al. Isolation and characterization of hematopoietic progenitor/stem cells in 5q-deleted myelodysplastic syndromes: evidence for involvement at the hematopoietic stem cell level. Blood 2000;96:2012-21.

[20] Nilsson L, Astrand-Grundstrom I, Anderson K, Ardvidsson I, Hokland P, Bryder D, et al. Involvement and functional impairment of the CD34CD38-Thy-1 hematopoietic stem cell pool in myelodysplastic syndromes with trisomy 8 . Blood 2002:100:259-67.

[21] Miura I, Kobayashi Y, Takahashi N, Saitoh K, Miura AB. Involvement of natural killer cells in patients with myelodysplastic syndromes carryng monosomy 7 revealed by the application of fluorescence in situ hybridization to cell collected by means of fluorescence-activated cell sorting. $\mathrm{Br} \mathrm{J}$ Haematol 2000;110:876-9.

[22] Clappier E, Cuccuini W, Kalota A, Crinquette A, Cavuela JM, Dik WA, et al. The CMYB locus is involved in chromosomal translocation and genomic duplications in human T-cell acute leukemia (T-ALL), the translocation defining a new T-ALL subtype in very young children. Blood 2007;110:1251-61.

[23] Radtke F, Wilson A, Robson MacDonald H. Notch signaling in T- and B-cel development. Curr Opin Immunol 2004;16:174-9.

[24] Ferrando AA. The role of NOTCH1 signaling in T-ALL. Hematol Am Soc Hemato Educ Program 2009:353-61.

[25] Chu H, Heiser D, Li L, Collector M, Huso D, Sharkis SJ, et al. FLT3-ITD knock-in impairs hematopoietic stem cell quiescence/homeostasis leading to myeloproliferative neoplasms. Cell Stem cell 2012;11:346-58.

[26] Thanasopoulou A, Tzankov A, Schwaller J. Potent cooperation between the NUP98-NSD1 fusion and FLT3-ITD mutation in acute myeloid leukemia induction. Haematologica 2014, http://dx.doi.org/10.3324/haematol.2013.

[27] Kato N, Kitaura J, Doki N, Komeno Y, Watanabe-Okochi N, Togami K, et al. Two types of $\mathrm{C} / \mathrm{EBP} \alpha$ mutations play distinct but collaborative roles in leukemogenesis: lessons from clinical data and BMT models. Blood 2011;117: 221-33. 